REVIEW PROF-2101

\title{
ANATOMY RESOURCE CENTRE
}

\author{
Dr. Shafiq Ullah, Dr. Shahid Mansoor Nizami, Dr. M. Zia Ur Rehman
}

ABSTRACT... It has been seen that just delivering the lectures of anatomy followed by dissection may fail to produce a long lasting understanding of the subject. The students are also unable to appreciate the importance of clinical anatomy integrated within various medical disciplines. A medical college or university may look at restructuring the medical curriculum with an anatomy resource centre which can have a pivotal influence on self-directed learning. Objectives: (1) To prepare an innovative resource centre for teachers. (2). To train student to achieve sufficient knowledge, skill and attitude when given a problem-solving exercise. Methodology: The resource centre is equipped with routine cadaveric dissection. Such gross structural relationships are made more meaningful by the use of living anatomy such as conventional radiographs, CT, MRI, ultrasound, laparoscopic, videos and surface anatomy. Simultaneous presence of microscopic anatomy (histology) can help to understand cell biology and molecular medicine in great detail. It is also necessary to use plastic models to overcome the complexity of the structures such as perineum and joints. Web-based computer sites can supplement the effort and to achieve what is called 'self-directed assessment skill'. Once the students are aware of the normal structures, they can be challenged with abnormal structures or tissues. An anatomy resource centre thus, can be integrated with various disciplines. However, it is felt that an efficient clinical anatomy curriculum can only lead to the success in developing an innovative anatomy resource centre for teachers and students.

Key words: Educational Resources, Web-base Learning, Summative Examination.

Article Citation

Shafiq Ullah, Nizami SM, Zia ur Rehman M, Anjum I. Anatomy resource centre. Professional Med J 2013;20(2): $171-176$.

\section{INTRODUCTION}

Anatomy has arguably the longest history as a discipline in formalized medical education". Human anatomy is not just the study of structure or morphology but the human anatomist is similar to "a geographer of the human body"2. Regarded as an integral component of the medical curriculum, a sound knowledge in human anatomy prepares the medical undergraduate for his future training in the clinical disciplines. However, the teaching of anatomy in the new millennium requires significant changes ${ }^{3}$. A medical college therefore should re-evaluate its own curriculum in terms of what the students need to learn. Since anatomy is exposed to the students at the outset of a curriculum ${ }^{4}$, medical college therefore should be careful in planning students-directed anatomy objectives and how they are going to be delivered. This is particularly important as the current pressure to reduce the hours devoted to learning anatomy may even complicate the entire planning ${ }^{5,6}$. The students are exposed to various state-of-the-art modalities so that the future physicians appreciate the logic behind understanding living and clinical anatomy. The exponential growth of medical knowledge creates enormous problem for designing the medical school curriculum ${ }^{7}$. Some of the medical colleges have reduced the hours necessary for anatomy education $n^{5,6}$. The traditional lecture-based anatomy teaching has been shown to have a very little effect on learners looking for lasting understanding ${ }^{7}$. It has been reported that learning in a small group environment enhances the knowledge and understanding the subject ${ }^{8}$. Teaching in an integrated way using various modalities available is considered ideal as it mimics examining common clinical cases ${ }^{9}$. A place is developed to teach more anatomy in less time. To provide more instructional technology for most efficient learning ${ }^{10}$.

\section{B. INTEGRATED RESOURCE CENTRE}

A centre is organized to effectively integrate anatomy with various other disciplines. An ideal place for teachers and teaching. In designing an anatomy resource centre, the principles of three curricular models may be considered: traditional, integrated 
problem-based and system-oriented ${ }^{8}$. The entire resource centre thus may be divided into specific areas for dissection, prosection, audiovisual, radiographs/holograms, cross-sectional anatomy, self-directed learning, ultrasound, embryology, molecular medicine, pathological specimens, computers and demonstration. Histology slides and CDs are made available within a module system, a separate area for histology equipped with video monitors may be also available to the teachers and the students.

A module of a resource centre is defined here as a set of materials contained in a learning carrel and addressing a particular set of integrated objectives $^{9,12,13}$. Each module is centered on a theme of a specific unit or a system explaining various concepts. These modules and the arrangements of the carrels have pivotal influence on the resource centre and constitute the ideal place for teachers and teaching including self-directed learning.

A typical carrel (module) should have labeled palastinated specimens/prosections, radiographs/ CT/ MRI to show the same area of interest, models/charts to simplify the structural arrangements, case studies with questions and answers to strengthen the concepts of functional and clinical anatomy and histology/ pathological specimens to identify the abnormalities of the specific area/organ. Computer-assisted materials, videocassettes (such as laparoscopy), ultrasound and a structured program of living anatomy in the clinical professional skills curriculum facilitate such an arrangement.

Digital technology has added a new dimension in teaching anatomy. The anatomy resource centre provides various modalities that prove to be a gateway for acquiring all the essential skills in anatomy from multiple perspectives.

\section{Web Base Learning: Living Anatomy}

Living anatomy is defined as the anatomy revealed on living humans, is gaining importance in modern anatomy education, and has even been considered to replace cadaver-based anatomy study. It is important to introduce the modalities through which living anatomy can be studied and explore the feasibility of using them to replace cadaver-based anatomy. We believe that the study of anatomy via the three main modalities of living anatomy, namely surface anatomy, medical imaging and surgical procedures, rely on a foundation of sound knowledge of the threedimensional anatomy.

\section{(a) The Surface Anatomy}

The surface anatomy forms the obvious connection between basic gross anatomy and clinical practice, because it is the basis of physical examination. Also included under surface anatomy are the projection technique and body painting. Both use the body surface as the medium for presentation of images of the internal anatomy.

\section{(b) Anatomy by Medical Imaging}

The most powerful tool available nowadays for the study of living anatomy is no doubt the medical imaging technologies, such as X-ray, CT, MRI, and ultrasound and laparoscope. Their primary purpose is to reveal anatomy, normal and pathological, in patients. The use of these medical images in the teaching of anatomy is a by-product of these medical imaging technologies. Radiographs, CT, MRI, ultrasound, laparoscope, plastinated specimens, models, charts, histological slides, bones, dissection, web based CD packages, diagrams and case studies with relevant questions and answers are the wide range of available facilities in the anatomy resource centre. These new systems promise to make broadbased training experiences available for students at all levels. Medical students could acquire proficiency and gain confidence in the ability to perform a wide variety of techniques long before they need to use them 
clinically.

\section{(c) Surgical Anatomy}

Simulated encounters, in combination models and dissection could increase the depth and breadth of students' exposure to medical problems and enhance the acquisition of clinical skills. Laparoscopic video/elearning facility also provides an amalgamation of the principles that are applied to the structures both in the dead and live scenario. With the integrated teaching methodology in medicine, the anatomy resource centre thus can have a pivotal influence on the integration of various subjects throughout the curriculum.

\section{Integrated Teaching of Anatomy}

Both intra-departmental and inter-departmental integration are necessary. Thus horizontal as well vertical integrated system of learning brings a thorough understanding of the subject or the topic. However in order to achieve this goal any system can be approached in a dynamic way. For example, one of the important concepts the students are likely to encounter in cardiovascular system is "cardiac contractility". The cardiovascular learning station will contain the models of the heart, specimens of various parts of heart, normal and abnormal radiographs of heart, labeled plastinated specimens, CT scans of heart showing various positions of heart and its structural relationship with other vital organs in the mediastinum, histological slides to study the features of cardiac cells, diagrams /charts to emphasize the physiology of excitation-contraction coupling, charts to pinpoint the neural control and embryological aspect of cardiac development and its anomalies and how they interfere with the normal position and contractility of heart, CD highlighting the congestive heart failure with audio visual images and question charts with answers for self study ${ }^{6}$. Apart from enhancing the learning process, the anatomy resource centre also provides a great opportunity to incorporate a) peer assisted learning b) small group discussions.

\section{a) Peer Assisted Learning}

This has proved to be extremely beneficial and have yielded excellent student understanding. The students here get an opportunity to listen to the Professors in the lecture hall and then the same topic is learned in a lab environment with display of plastinated specimens, cadavers and radiographic imaging materials.

\section{b) Small Group Discussions}

Small group discussions can be very well practiced within large lecture halls and the discussions can be monitored and supervised by the faculty members. This allows the students to actively participate in the process of learning and removes the traditional student/ teacher barrier. Small group teaching has been widely and successfully applied in anatomy teaching ${ }^{9,14-17}$. If students are unable to complete the assigned tasks, guidance is then provided to help them to accomplish the tasks. ${ }^{8}$. The small group discussion also significantly improves the communication skills among the students.

\section{Communication Skills}

Since communication with the patient is the key in elucidating the proper history and symptoms (which in turn becomes a basis for a preliminary diagnosis), medical education has always stressed upon the importance of communication skills in medical students. By practicing small group discussions in the class particularly in professional skill course, we encourage more student-to-student interaction, which primarily helps them to develop the basic communication skills.

\section{Hands on Experience}

With all the modalities available in the anatomy resource centre students can get a good amount of hands on experience that will help to understand and retain the acquired knowledge. Since, clinicians encounter anatomy in their everyday clinical practice through living anatomy, it is therefore essential to teach students anatomy in these contexts right from the 
beginning. It is a widely held view that dissection gives students a 3D view of human anatomy and reinforces knowledge acquired in lectures ${ }^{18,19}$. Undoubtedly modern 3D imaging methods give better views of the internal structures of individual living patients during medical procedures that can be superior to those observed during dissection. It may be pointed out that cadavers may also present a number of disadvantages such as color, smell, texture and cannot be palpated or auscultated as in a real life ${ }^{20}$.

\section{LATEST TRENDS}

Anatomy department may use a number of digital video cameras and associated software for video links between the computers of faculty and students. These cameras should be able to take pictures in high resolution color and send them to the students over the internet. This is particularly useful in a visual subject such as anatomy. Students would be able to contact resource persons for seminars without having to gather in one site and this is a great advantage particularly if the interaction is needed from a distance. There is no doubt that in the 21 st century, students are becoming completely dependent upon the world wide web (www) for acquiring information and to seek additional resources. As medical educators, we have to modify our attitude towards the whole process of teaching basic medical sciences including anatomy. The entire world of medical education is moving towards the direction of applied way of teaching and learning so as to provide the students the clinical importance of the basic topics they learn in the medical curriculum. The department of anatomy is becoming more involved in use of the world wide web for dissemination of teaching and research material ${ }^{10}$. Accordingly, the anatomy departments may have to modify its www page for interactive access of its teaching programmes.

\section{THE ASSESSMENT SYSTEM: TEACHING LEARNING OUTCOME}

Since anatomy is standing right at the entrance of the bridge leading from college life to professional institute, we have the unique opportunity to challenge these individuals in ways that they have never been challenged. The learning in anatomy resource centre differs from a regular lab system with regard to the accumulation of achieved knowledge. Instead of successively ordered topics, the student must learn to integrate the fundamentals of anatomy with various related topics and also with the recent developments in the field of anatomy. Assessment system has pivotal influence on student's education and therefore it is necessary to match the assessment to the learning process. The purpose of assessment is to understand the quality of student learning and this is achieved through incorporating standard and different tools of testing throughout the curriculum. These tools of testing allow space to assess the various domains of learning, i.e. knowledge, skills and logical reasoning ${ }^{9,17}$.

\section{Continuous Assessment and Formative/Summative Examination}

Assessment is most effective when it reflects an understanding of learning as multidimensional, integrated, and revealed in performance over time. In that way continuous assessment encourages consistent and effective learning throughout the course and can be conducted in myriad ways such as online quizzes, lab worksheets, group projects, homework assignments, lecture quizzes, classroom participations, mid-term test, and practice sessions.

End-of-semester exam is usually summative in nature. The questions are asked in the form of multiple choice question (MCQ), short answer question (SAQ) and objective-structured practical examination (OSPE). These questions are based on the UHS format where there is less focus on the direct identification of the structures and more emphasize given to the secondary questions. Care is taken to ensure appropriate distribution of questions from various topics keeping it relevant to the learning objectives of 
the course. Accordingly, a blue-print is developed well before the exam schedule and is distributed to the faculties for development of the questions. These mock exams help students understand their strengths and weaknesses in the topic and focus their preparation for the real exam. Very often the questions are also put in an objective structured clinical examination (OSCE). The short answer questions are mostly related to basic understanding of clinical cases. Following a clinical scenario, the students are asked to answer the basic mechanisms involved.

\section{Self-Directed Assessment}

This is probably the best form in which a student can feel confident in his/her teaching-learning outcome. Therefore, the anatomy resource centre must provide enough facilities to create an environment so that a student can challenge the depth of knowledge, skill and attitude towards problem solving exercises. The anatomy resource centre must be equipped with various facilities as indicated earlier including computer assisted program commercially available.

\section{Students' Feedback on Assessment}

One of the most important resources for sustaining professional development in teaching is getting feedback from students. To understand the student learning in the anatomy resource centre surveys are conducted in which the feedback should be focused on various aspects such as facilities available in the anatomy resource centre, influence of facilities on learning, effects of integration in anatomy, results of learning $3 \mathrm{D}$ and $2 \mathrm{D}$ anatomy together and finally the questions (and answers) of the recent exam held.

Student feedback is collected through questionnaire and their representation on staff-student committees, structured group discussions, one to one student interviews, e-mail, bulletin boards, student's diaries and/or log books.

\section{E. CONCLUSIONS}

A sound anatomy curriculum is essential based on the need of the $21^{\text {st }}$ century. Perhaps the time has come when the medical colleges across the world can present their anatomy resource centers in a new direction that will bring $21^{\text {st }}$ century technology to the students to make the learning objectives in a more effective manner. The strategies should be clear as the new face of the anatomy resource centre has a pivotal influence on integrated teaching and in relation to students' attention on the critical skill of thinking and assimilating new knowledge. The students can use an integrated anatomy resource centre more by spending less time in the traditional didactic anatomy lectures. Anatomy education is not only an essential part of the medical curriculum, but also helps to further the development of medical professionalism ${ }^{22}$. However, there are issues that have to be addressed. These changes in the teaching of Anatomy are likely to affect the training of medical students and the professional anatomist.

Copyright(C) 12 Dec, 2012.

\section{REFERENCES}

1. McLachlan JC, Patten D. Anatomy teaching: ghosts of the past, present and future. Med Educ 2006; 40:24353.

2. Guttmann GD, Drake RL, Trelease RB. To what extent is cadaver dissection necessary to learn medical gross anatomy? A debate forum.

3. Ganske I, Su T, Loukas M, Shaffer K. Teaching methods in anatomy courses in North American medical schools: the role of radiology. Acad Radiol 2006; 13:1038-46. Comment in: Acad Radiol 2006; 13:1444.

4. Collins TJ, Given RL, Hulsebosch CE, Miller BT. Status of gross anatomy in the US and Canada: Dilemma for the 21st century. Clin Anat 1994; 7: 275-96.

5. Drake RL, Lowrie DJ, Jr., Prewitt CM. Survey of gross anatomy, microscopic anatomy, neuroscience, and embryology courses in medical school curricula in the United States. Anat Rec 2002; 269: 118-22.

6. Heylings DJ. Anatomy 1999-2000: the curriculum, 
who teaches it and how? Med Educ 2002; 36: $702-$ 310.

7. Rizzolo LJ, Stewart WB, O'Brien M, Haims A, Rando W, Abrahams J, Dunne S, Wang S, Aden, M. Design principles for developing an efficient clinical anatomy course. Med Teach 2006; 28: 14251.

8. Chan LK, Ganguly PK. Evaluation of small group teaching in human gross anatomy in a Caribbean medical school. Anat Sci Educ 2008; 1: 19-22.

9. Ganguly PK, Chakravarty M, Abdul Latif N, Osman M, Abu-Hijleh M. Teaching of Anatomy in a Problem based curriculum at the Arabian Gulf University: The New Face of the Museum. Clin Anat 2003; 16: 256-61.

10. Kim S, Brinkley JF, Rosse C. Profile of on-line anatomy information resources: design and instructional implications. Clin Anat 2003; 16: 55-71.

11. Drake RL. Anatomy education in a changing medical curriculum. Kaibog Zassi 1999; 74: 487-90.

12. Zehr CL, Butler RG, Richardson RJ. Students' use of anatomy modules in problem-based medical education at McMaster University. Acad Med 1996; 71: 1015-7.

13. Abu-Hijleh MF, Kassab S, Al-Shboul Q, Ganguly PK. Evaluation of the teaching strategy of cardiovascular system in a problem-based curriculum: student perception. Adv Physiol Educ 2004; 28: 59-63.

14. Jacques, D. ABC of learning and teaching in medicine: Teaching small groups. $\mathrm{Br}$ Med J 2003; 326: 492-94.
15. Abu-Hijleh MF, Chakravarty M, Al-Shboul Q, et al. Structured problem-related anatomy demonstration: making order of random teaching events. Teach Learn Med 2005; 17: 68-72.

16. Swartz WJ. Using gross anatomy to teach and assess professionalism in the first year of medical School. Clin Anat 2006; 19: 437-41.

17. Ganguly PK, Sanii R. The new face of the old problem (letter to the [editor). Clin Anat 2006; 19: 778-79.

18. McLachlan JC. New path for teaching anatomy: living anatomy and medical imaging vs dissection. Anat Rec (PartB: New Anat) 2004;281;4-5.

19. Cottam WW. Adequacy of medical school gross anatomy education as perceived by certain postgraduate residency programs and anatomy course directors. Clin Anat 1999; 12: 55-65.

20. Ganguly PK, Chan LK. Living anatomy in the 21st century: how far We can go? SE Asian J Med Educ 2008; $2: 52-7$

21. Chakravarty M, Latif NA, Abu-Hijleh MF, Osman M, Dharap AS, Ganguly PK. Assessment of Anatomy in a problem-based Medical 2004; 281: 4-5. Curriculum. Clin Anat 2005; 18: 131-6.

22. Rizzolo LJ, Stewart WB. Should we continue teaching anatomy by dissection when...? Anat Rec B New Anat 2006; 289:215-8.
AUTHOR(S):

1. DR. SHAFIQ ULLAH

Assistant Professor Anatomy

Nishtar Medical College, Multan

2. DR. SHAHID MANSOOR NIZAMI

Assistant Professor Anatomy

Nishtar Medical College, Multan

3. DR. MUHAMMAD ZIA UR REHMAN

Assistant Professor of Anatomy

Sheikh Zayed Medical College, Rahim Yar Khan
Correspondence Address:

Dr. Shafiq Ullah

Assistant Professor of Anatomy

Nishtar Medical College, Multan

waseemfsd99@yahoo.com 